\title{
Optimization Strategy of Sustainable Concentrated Photovoltaic Thermal (CPVT) System for Cooling
}

\author{
Muhammad Burhan ${ }^{1 *}$, Muhammad Wakil Shahzad ${ }^{1}$ and Kim Choon Ng${ }^{1}$ \\ ${ }^{1}$ Water Desalination and Reuse Centre, Biological and Environmental Science \& Engineering \\ (BESE), King Abdullah University of Science \& Technology, Thuwal 23955-6900, Saudi \\ Arabia \\ *muhammad.burhan@kaust.edu.sa
}

\begin{abstract}
Renewable energy resources are susceptible to intermittent power supply and their standalone operation has prime importance for steady power supply. Solar energy resources have high global availability and potential among all energy sources. Most of areas with high solar energy potential have either dry hot or tropical climate. A major portion of primary energy supply for such area is utilized in their cooling energy needs. In this chapter, a sustainable approach for cooling needs has been proposed using solar energy based highly efficient concentrated photovoltaic (CPV). A combined cooling system, based upon mechanical vapour compression (MVC) and adsorption chillers have been considered. The MVC chiller utilizes the produced electricity by the third generation multi-junction solar cells (MJC). However, adsorption chiller is operated with thermal energy recovered from the cooling of CPV system, which also increases the system efficiency as high as $71 \%$. To handle intermittency, hydrogen production is used primary energy storage system, along with the hot water storage. The complete system configuration is then optimized for standalone operation with optimum components size and minimum cost, using microgenetic algorithm according to proposed optimization strategy.
\end{abstract}

Keywords: CPVT, micro-GA, Cooling, Solar Efficiency, Hybrid, Sustainable.

\section{$1 \quad$ Background}

The sustainability of an energy source depends upon its potential, availability and environmental impact. Currently, fossil fuel based power systems have potential to meet global energy need with flexible availability, as per demand, without any interruption. However, their hazardous emissions are pushing our environment towards irreparable damage. If we look at the renewable energy resources, beside their energy potential, they don't offer steady power supply which is the main requirement of power producing system i.e. to meet fluctuating demand at any time of the day [1-6]. The intermittency and low energy density of renewable energy resources limit their use as primary energy supply $[7,8]$. On the other hand, application of produced energy is also very important to find the sustainable solution. The energy consumption for cooling application is huge, which can go to $40-50 \%$ of the electricity production of 
some countries especially in desert and tropical regions [9]. These hot climate regions are also rich in terms of their solar energy potential [10,11]. The only need is to use this solar energy potential effectively and efficiently to fulfill their energy needs [1213].

Solar radiations hitting the earth surface have potential higher than the global energy need [14]. However, they are intermittent in nature, with non-uniform availability during diurnal period and zero availability during nocturnal period. To be used as steady power source, sustainable energy storage is needed and hydrogen production provide a long term and reliable solution for solar energy systems [15]. Electrolytic hydrogen production from water can work in a closed loop as the electricity can be produced back in fuel cell with water production, assuming no loss. Therefore, such energy storage configuration can also be used in remote areas without any external supply. On the other hand, conventional electrochemical energy storage in batteries is only suitable for small scale systems, for short term solution [16].

One of the most important aspect of energy systems is their efficiency and for the solar energy, the system efficiency is very important as it will reduce installation space requirements. For cooling application, mechanical vapour compression (MVC) chillers provide most simple, reliable and efficient solution, by using electricity. However, to produce electricity from solar energy, photovoltaic systems provide most simple configuration for such application. But if we look at the photovoltaic market, it is fully dominated by the single junction based solar cells which can only respond to certain portion of spectrum, thereby, having limitation on their solar energy conversion efficiency [17-19]. Third generation, multi-junction, solar cell based concentrated photovoltaic (CPV) system provides highest efficiency among all photovoltaic technology. Up till now, highest efficiency of $46 \%$ has been recorded for multijunction solar cell $[20,21]$. Solar to hydrogen conversion efficiency of $24 \%$ has been reported for CPV under lab conditions and $18 \%$ under field conditions [22], which is almost 2-3 fold higher than only electricity production efficiency of conventional PV [23,24]. Despite such potential, the market share of CPV is negligible. In addition, there are very few studies discussing the theoretical modelling and performance potential of concentrated photovoltaic (CPV) system. Even none of the commercial tool, related to optimization and simulation of renewable energy system i.e. INSEL, SOMES, HOMER [25], RAPSIM, ARES, TRNSYS + HYDROGEMS, SOLSIM [26] and iHOGA [27], have capability to analyse the concentrated photovoltaic (CPV) system.

Therefore, due to greenhouse gas emissions of fossil fuel based system and the increasing demand of cooling in the hot sunny regions, a sustainable system configuration is proposed as standalone solar system which employs the full potential of received solar energy by using concentrated photovoltaic (CPV) with thermal heat recovery. For steady power supply to the chillers, hydrogen and hot water based energy storage systems are used to supply electricity and heat according to the system need. As the literature is lacking detailed performance model for CPV system, especially for cooling, therefore, in this chapter, a detailed model and standalone system optimization strategy of CPVT (CPV + Thermal) system is presented for a combined configuration of MVC and adsorption chiller. To counter intermittency of received solar en- 
ergy, hydrogen and hot water based energy storage system is proposed whose detailed energy management strategy is also presented. As the system capture the full potential of received solar energy by producing electricity from CPV and revering water heat through solar thermal circuit, therefore, a system efficiency of $71 \%$ is expected for solar energy conversion. The system performance model is based upon the temperature and concentration characteristics of multi-junction solar cell. Such combined system is then optimized for the size of each component to have minimum capital cost and uninterrupted output.

\section{Standalone CPVT-Hydrogen System}

Fig. 1 shows the configuration of sustainable combined cooling system, utilizing concentrated photovoltaic (CPV) as solar energy system. The proposed configuration is operating in standalone operation without any external supply of power and resources (assuming no leak) as it is utilizing combined energy storage system i.e. hydrogen production and hot water storage. The hydrogen is produced through electrolysis of water using the excess electricity produced by the CPV system, after fulfilling the energy need of the load and system. The produced hydrogen and oxygen are then stored into cylinders to supply back electricity using fuel cell, in case of power deficiency that may happen during cloudy or nocturnal period. The electricity produced by CPV system is supplied to the main DC line through maximum power point tracking (MPPT) devices and DC/DC converter. All of the power consuming devices e.g. mechanical vapor compression (MVC) chiller, gas compressor, circulating pumps and solar trackers, are linked to this main DC line through appropriate voltage converter, due to difference between produced and required voltage. As CPV can only accepts beam radiations, therefore, multi-junction solar cells (MJC) based CPV modules are mounted onto two axis solar tracking units, for which the power is also supplied from main CPV system. The CPV modules in current study can be of any type either reflector based units i.e. cassegrain assembly or refraction based units which utilize Fresnel lens, as the performance model discussed in this study is free from concentration assembly type and considers their concentration ratio and optical properties.

The main cooling system is based upon the mechanical vapor compression (MVC) chiller for which the electricity is supplied by CPV system and hydrogen based energy storage unit. CPV units need heat rejection system for their safe operation. As $\mathrm{CPV}$ units operate at high concentration, therefore, a large portion of this waste heat is available at high temperature. This heat, instead of rejecting to environment is recovered and stored in form of hot water storage. This thermal heat storage is then used to operate an auxiliary adsorption cooling unit which not only provides extra cooling from this recovered energy but also increases the overall efficiency of the CPV system up to $71 \%$.

In the next section a detailed performance model for each individual component of the proposed solar operated sustainable cooling system. The main target for this performance model development is to design a standalone system with uninterrupted 
supply to the customer needs, irrespective of time and the load requirement but at minimum cost.

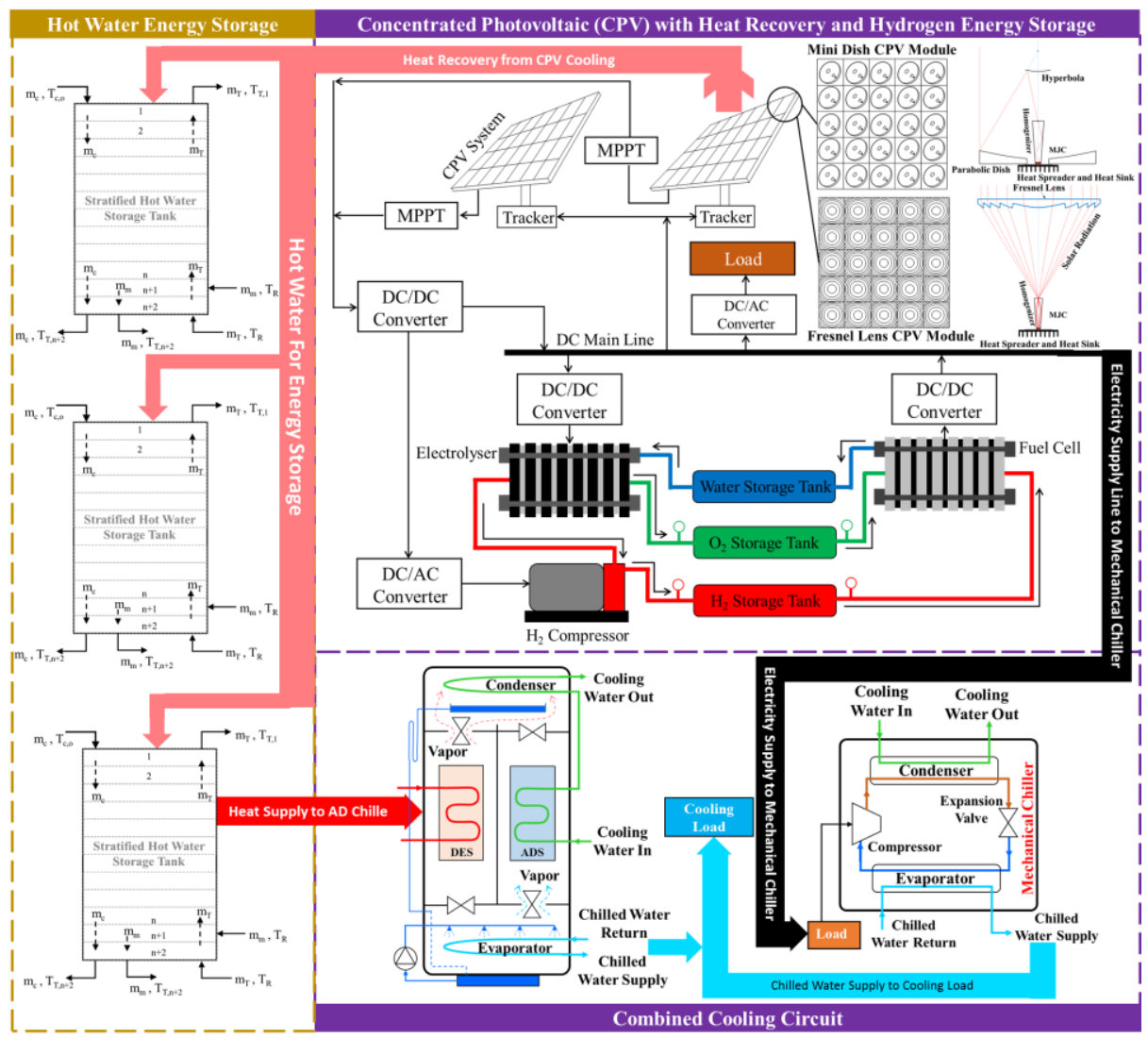

Fig.1. Proposed System Configuration for Sustainable Cooling Solution using Solar Energy.

\section{Performance Model Development}

As mentioned in the previous section, the target of proposed system to provide uninterrupted supply without any external assistance, utilizing solar energy. Therefore, detailed performance model for each sub-system is developed in this section so that overall system size can be optimized for steady power supply, even during cloudy and nocturnal period, with minimum cost i.e. avoiding oversized system. Such sustainable cooling system will not only eliminate solar intermittency but it will also work during nocturnal period with maximum system efficiency. Fig. 2 shows the energy management strategy with which individual components are connecting and interacting with each other. The direct normal irradiance (DNI) or beam radiations intensity data is provided as solar energy input to the system model along with the ambient tempera- 
ture values as it will affect the overall CPV operating conditions. According to concentrating assembly configuration for CPV modules i.e. refraction or reflection based design, and their optical properties, the concentration at the cell area is calculated which then gives the power output of the cell through considered cell characteristics. By analyzing the heat loss and the performance of hot water energy recovery circuit, the stored thermal energy is determined for the operation of adsorption chiller. Depending upon the cooling load requirement, the excess energy produced by the CPV system is determined, which is then converted into hydrogen and oxygen as energy storage. In case of power deficiency, stored gases supply back electricity using fuel cell. The performance model for individual component is as follows.

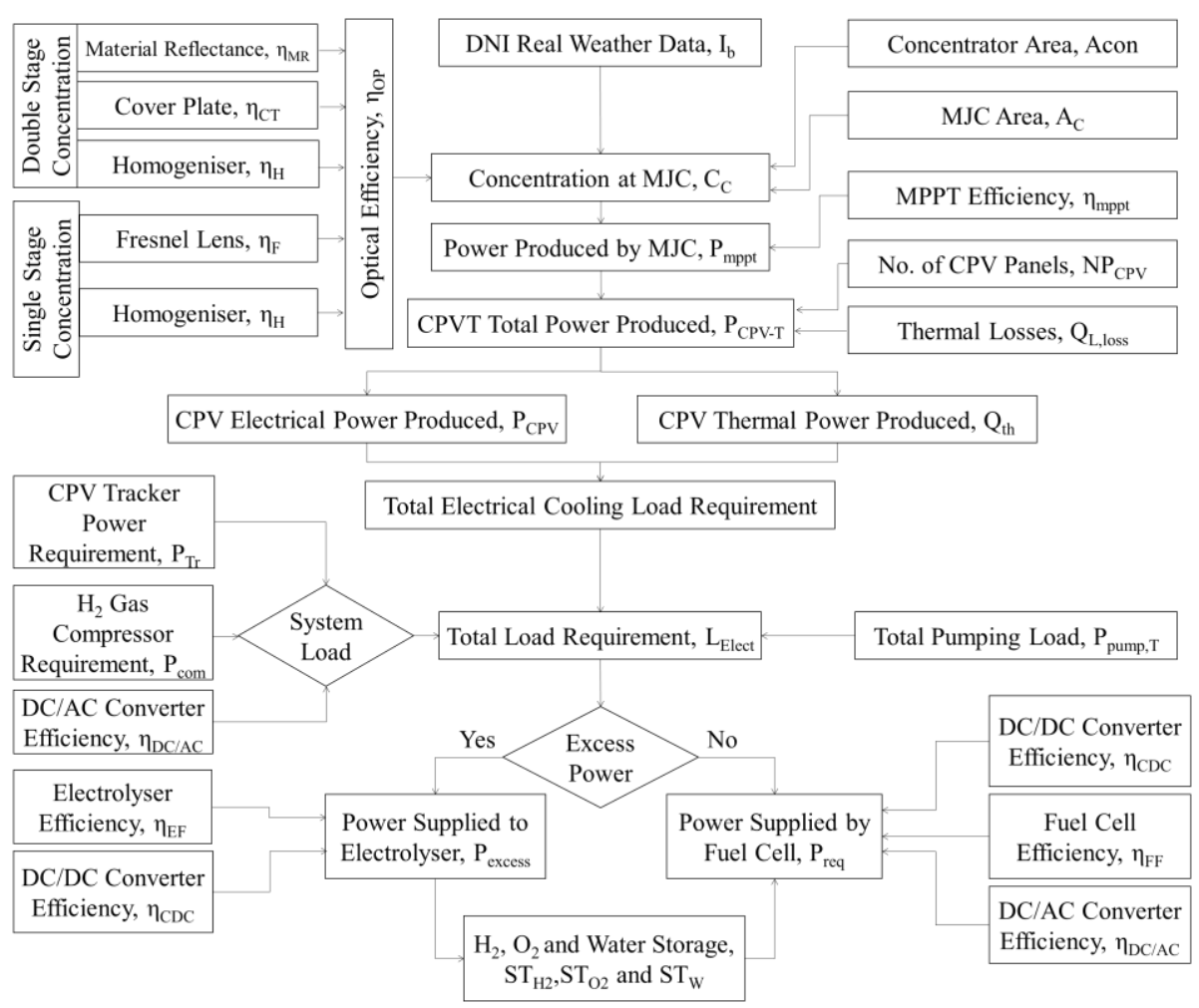

Fig.2. Energy Management Order for Combined Cooling System using CPV-Thermal System.

\subsection{Concentrated Photovoltaic (CPV) System}

This sub-section is related to the upper part of Fig. 2 which gives the electrical power output of the CPV from the beam solar energy input. Based upon the characteristics of the multi-junction solar cell at different cell temperature and concentration values, the total power output of the CPV system can be calculated. In order to simulate the power output of single solar cell, a simple diode model is used which is modified for the solar cell operating under concentration, as given by equation (1) [28]. 


$$
P_{C}=I_{C} V_{C}=V_{C}\left[I_{o}\left\{\exp \left(\frac{q V_{C}}{n_{C} k T_{C}}\right)-1\right\}-I_{S C}\right]
$$

By putting the open circuit voltage ' $\mathrm{V}=\mathrm{V}_{\mathrm{OC}}$ ' condition of zero current ' $\mathrm{I}=0$ ' in equation (1), the diode saturation current factor ' $\mathrm{I}_{\mathrm{o}}$ ' factor can be found by equation (2).

$$
I_{o}=\frac{I_{S C}}{\left[\exp \left(\frac{q V_{O C}}{n_{C} k T_{C}}\right)-1\right]}
$$

For current study, a triple junction solar cell i.e. InGaP/InGaAs/Ge is considered for which the concentration and temperature characteristics of open circuit voltage and short circuit currents factors are given in Fig. 3 and 4. If the performance characteristics of solar cell are known at its rated temperature of $25^{\circ} \mathrm{C}$ and the corresponding temperature/concentration factors are known then the values of ' $\mathrm{V}_{\mathrm{OC}}$ ' and ' $\mathrm{I}_{\mathrm{SC}}$ ' at any operating condition are given by equations (3) and (4).

$$
\begin{gathered}
V_{O C}\left(T_{C}, C_{C}\right)=\left[V_{O C}\left(\text { at } 25^{\circ} C\right)\right]_{C}+\left(T_{C}-25\right)\left[\frac{d V_{O C}}{d T_{C}}\right]_{C} \\
I_{S C}\left(T_{C}, C_{C}\right)=\left[I_{S C}\left(\text { at } 25^{\circ} C\right)\right]_{C}+\left(T_{C}-25\right)\left[\frac{d I_{S C}}{d T_{C}}\right]_{C}
\end{gathered}
$$

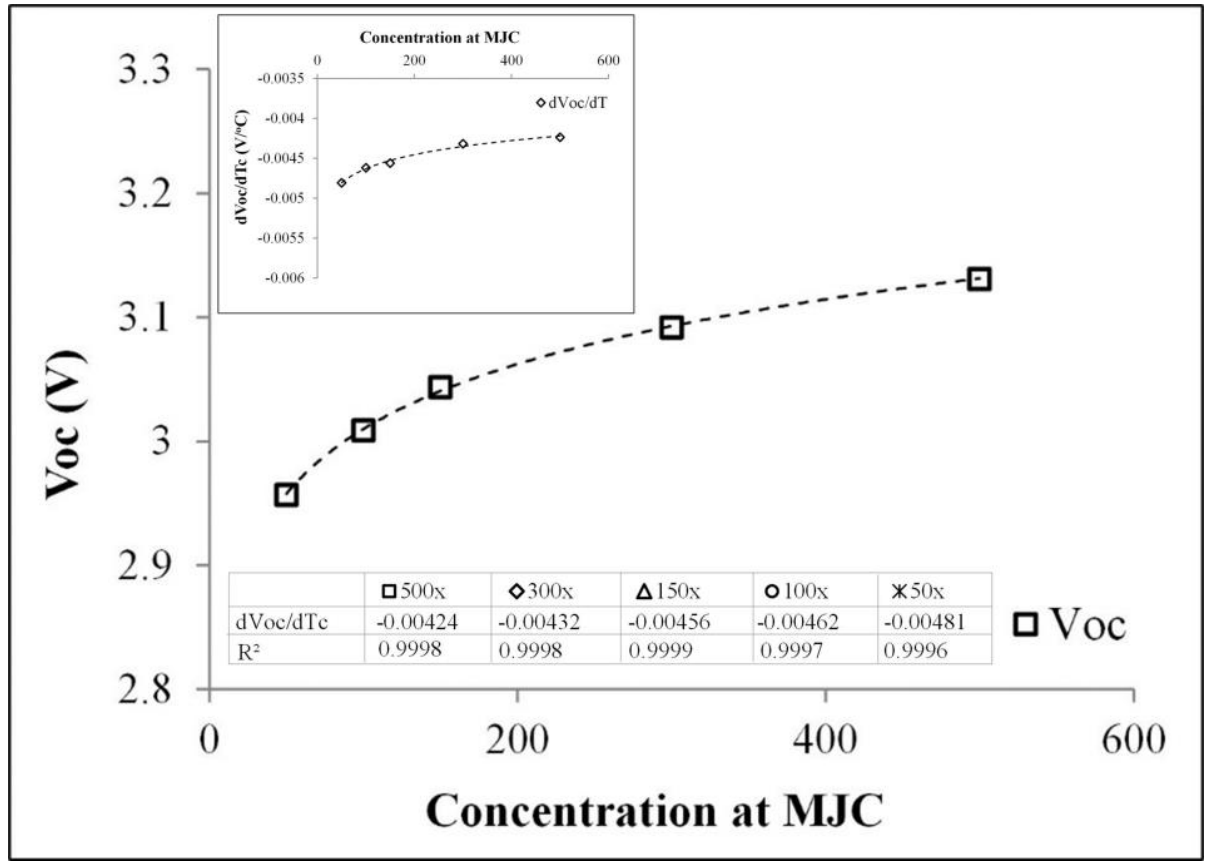

Fig.3. Open Circuit Voltage Characteristics for Multi-junction InGaP/InGaAs/Ge Solar Cell. 


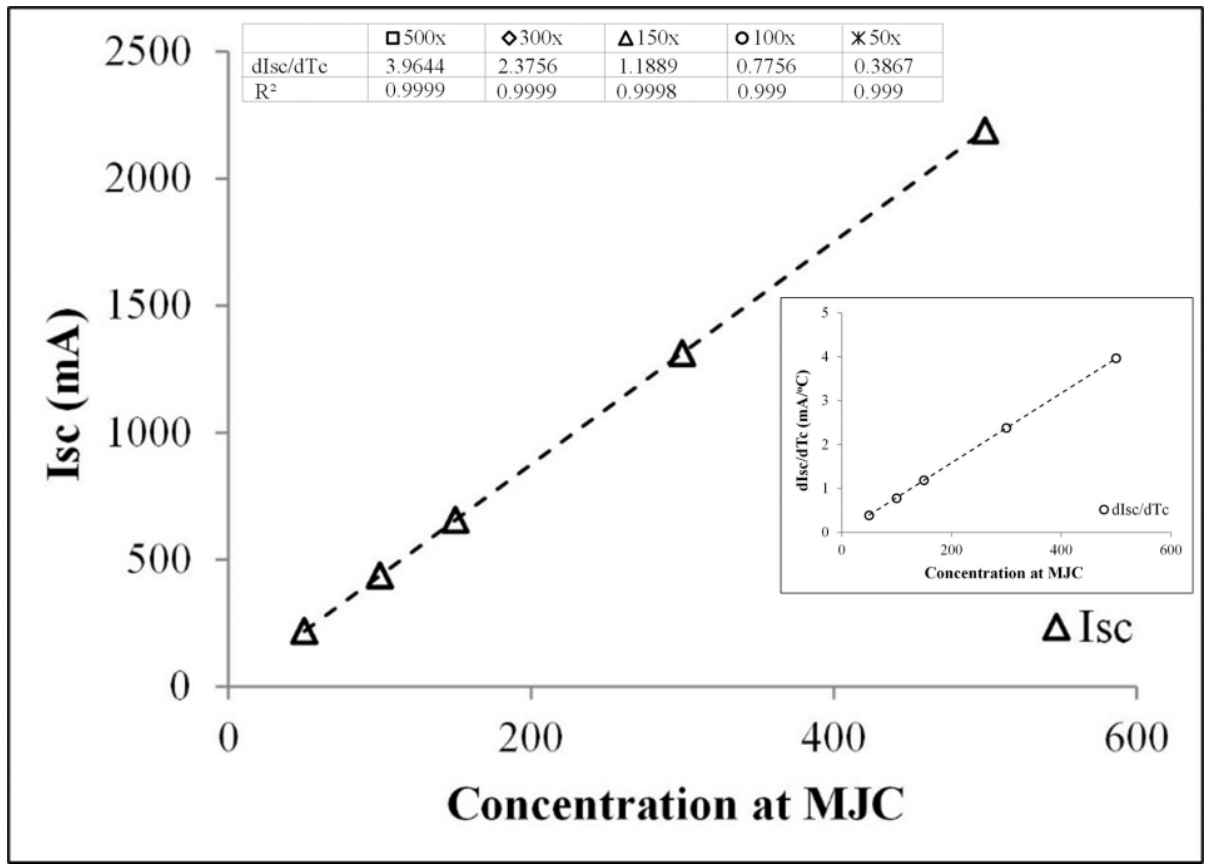

Fig.4. Short Circuit Current Characteristics for Multi-junction InGaP/InGaAs/Ge Solar Cell.

As the performance of multi-junction solar cell (MJC) is depending upon the concentration at cell area, therefore, based upon received direct normal irradiance (DNI), area ratio of concentrator ' $\mathrm{A}_{\mathrm{con}}$ ' and solar cell ' $\mathrm{A}_{\mathrm{C}}$ ', and the optical efficiency of concentrating assembly, the concentration at cell area is given by equation (5).

$$
C_{C}=I_{b} \times \frac{A_{c o n}}{A_{C}} \times \eta_{O P}
$$

The optical efficiency of concentrating assembly is depending upon its construction i.e. single stage refraction or double stage reflection. The single stage refraction is based upon a single Fresnel lens as concentrator, with glass prism rod as homogeniser. However, for double stage reflection, a pair of optically coated reflectors i.e. parabolic and hyperbolic, are used in cassegrain arrangement with glass prism rod as homogeniser. Therefore, equations (6A) and (6B) provide the optical efficiency calculation for single stage and double stage concentrating assemblies, which depends upon, in fact, the optical absorbance and reflectance of respective components.

Or

$$
\eta_{O P}=\eta_{F} \times \eta_{H}
$$

$$
\eta_{O P}=\eta_{P} \times \eta_{S} \times \eta_{H}
$$

As mentioned before, another performance parameter that affect the solar cell performance, is its operating temperature. The cell temperature is taken as $40^{\circ} \mathrm{C}$ higher than the ambient temperature as the difference between cell and back plate temperature is approximately $10^{\circ} \mathrm{C}$ [29] and a temperature difference of $20-30^{\circ} \mathrm{C}$ is taken between 
back plate and the ambient temperature. By gathering the values of all the performance parameter, the net power output by the CPV system can be calculated from equation (7).

$$
P_{C P V}=\eta_{D C / A C} \times \eta_{C D C} \times \eta_{T r} \times P_{m p p t} \times N_{C M} \times N P_{C P V}
$$

In above equation, the power consumption by CPV system itself is also considered in form of fraction factors which are related to solar tracking unit, DC/DC and DC/AC converters. The voltage converters have certain efficiency, thereby some power is dissipated during voltage conversion. On the other hand, the power consumption by trackers should only be considered during diurnal period i.e. from sunrise to sunset, which can be calculated from solar geometry model [30]. All of the constant parameters related to the discussed performance models are given in table 1. For Fresnel lens based single stage concentration, the optical efficiency of $72-73 \%$ [31] is considered as Fresnel lens has transmission efficiency of $90 \%$, due to absorbance of PMMA material of lens, and the receiver efficiency of $92 \%$ which is due the loss at the inlet aperture of the Fresnel lens. For cassegrain reflectors based double stage concentration, the optical efficiency of $85 \%$ can be considered as silver coated reflectors have reflective efficiency of $98 \%$ [32], with further $5 \%$ and $1 \%$ loss in glass cover plate and homogeniser, respectively. In this chapter, a lower value of $72 \%$ is considered as the optical efficiency of the concentrating assembly.

Table 1. Constant Parameters for Proposed Performance Model.

\begin{tabular}{llll}
\hline Parameter & Value & Parameter & Value \\
\hline $\mathrm{q}($ Coulomb $)$ & $1.6021765 \times 10^{-19}$ & $\mathrm{~F}($ As mol-1) & 96,485 \\
$\mathrm{k}\left(\mathrm{m}^{2} \mathrm{kgs}^{-2} \mathrm{~K}^{-1}\right)$ & $1.3806488 \times 10^{-23}$ & $\mathrm{t}_{1}\left(\mathrm{~m}^{2} \mathrm{~A}^{-1}\right)$ & $1.599 \times 10^{-2}$ \\
$\mathrm{n}_{\mathrm{C}}$ & 2 & $\mathrm{t}_{2}\left(\mathrm{~m}^{2} \mathrm{~A}^{-1}{ }^{\circ} \mathrm{C}^{-1}\right)$ & -1.302 \\
$\eta_{\mathrm{mppt}}$ & $85 \%$ & $\mathrm{t}_{3}\left(\mathrm{~m}^{2} \mathrm{~A}^{-1}{ }^{\circ} \mathrm{C}^{-2}\right)$ & $4.213 \times 10^{2}$ \\
$\eta_{\mathrm{DC} / \mathrm{AC}}$ & $90 \%$ & $\mathrm{n}$ & 2 \\
$\eta_{\mathrm{CDC}}$ & $95 \%$ & $\mathrm{U}_{\mathrm{o}}(\mathrm{mV})$ & 1065 \\
$\mathrm{U}_{\text {rev }}(\mathrm{V})$ & 1.229 & $\mathrm{~b}\left(\mathrm{mV} \mathrm{dec}{ }^{-1}\right)$ & 80 \\
$\mathrm{r}_{1}\left(\Omega \mathrm{m}^{2}\right)$ & $7.331 \times 10^{-5}$ & $\mathrm{R}\left(\Omega \mathrm{cm}^{-2}\right)$ & 0.438 \\
$\mathrm{r}_{2}\left(\Omega \mathrm{m}^{2}{ }^{\circ} \mathrm{C}^{-1}\right)$ & $-1.107 \times 10^{-7}$ & $\mathrm{M}_{\mathrm{H} 2}(\mathrm{~g} / \mathrm{mol})$ & 2.0159 \\
$\mathrm{~S}_{1}(\mathrm{~V})$ & $1.586 \times 10^{-1}$ & $\mathrm{CPH}(\mathrm{J} / \mathrm{kg} \cdot \mathrm{K})$ & 14304 \\
$\mathrm{~S}_{2}\left(\mathrm{~V}^{\circ} \mathrm{C}^{-1}\right)$ & $1.378 \times 10^{-3}$ & $\mathrm{~T}_{\mathrm{com}}(\mathrm{K})$ & 306 \\
$\mathrm{~A}_{\mathrm{E}}\left(\mathrm{m}^{2}\right)$ & 0.25 & $\eta_{\mathrm{DC} / \mathrm{AC}}(\%)$ & 90 \\
$\mathrm{~S}_{3}\left(\mathrm{~V}^{\circ} \mathrm{C}^{-2}\right)$ & $-1.606 \times 10^{-5}$ & $\eta_{\text {com }}(\%)$ & 70 \\
\hline
\end{tabular}

The factor ' $\mathrm{P}_{\mathrm{mppt}}$ ' in equation (7) is the power output from single multi-junction solar cell (MJC) at its maximum power point. As maximum power point tracking (MMPT) device is connected at the output of each CPV unit, therefore, it is assumed the CPV system is always operating at it maximum power point, with maximum possible efficiency at those operating conditions. In order to model this maximum power point tracking device, we know that its main purpose is to operate the solar cell at it 
maximum power point. Therefore, it depicts that when the solar cell operates its maximum power point, the MPPT device is working. By finding the expression for power output of solar cell at its maximum power point, we can actually model MPPT device, which can be done by equating the first derivative of solar cell power expression i.e. equation (1), to zero..

$$
\begin{gathered}
\frac{d P_{C}}{d V_{C}}=0 \\
\frac{d}{d V_{C}}\left[V_{C} I_{o}\left\{\exp \left(\frac{q V_{C}}{n_{C} k T_{C}}\right)-1\right\}-V_{C} I_{S C}\right]=0
\end{gathered}
$$

The above equation (9) can be further simplified to find the expressions for voltage, current and power produced by the solar cell at its maximum power point, given by equations (10), (11) and (12) respectively.

$$
\begin{gathered}
V_{m p p t}=V_{O C}-\frac{n_{C} k T_{C}}{q} \ln \left[1+\frac{q V_{m p p t}}{n_{C} k T_{C}}\right] \\
\mathrm{I}_{\text {mppt }}=\mathrm{I}_{\mathrm{o}}\left\{\exp \left(\frac{q V_{m p p t}}{n_{C} k T_{C}}\right)-1\right\}-I_{S C} \\
P_{m p p t}=\eta_{m p p t} \times I_{m p p t} \times V_{m p p t}
\end{gathered}
$$

\subsection{Alkaline Electrolyser}

This sub-section is related to the lower left part of Fig. 2 in which the excess power available is supplied to the electrolyser which has certain characteristics. In order to store the excess electricity produced by the CPV system, electrolysers are used to produced hydrogen and oxygen from water electrolysis. The performance and characteristics of electrolyser considered in this study is an alkaline based electrolyser unit as discussed in [33]. The power consumption and the production of gases is based upon the voltage-current (IV) characteristics of single electrolyser cell, which is joined in series with similar cell to form a complete unit. Therefore, the main design parameter for electrolyser unit is its power rating or size which depends upon the total number of cells connected in series. As the power characteristics of single electrolyser cell is known, therefore, by knowing the maximum excess power available, the maximum number of required cells for electrolyser units can be calculated by using equation (13).

$$
N_{E C}=\frac{\left(P_{M J C, \text { max }} \times N_{C M} \times N P_{C P V}\right)-L_{\text {min }}}{V_{E C, \text { max }} \times I_{E C, \text { max }}}
$$

In the numerator, the expression in bracket defined the maximum rated power of CPV unit, and the complete numerator expression gives the excess power available as ' $\mathrm{L}_{\text {min }}$ ' shows minimum load requirement. This excess available power is divided by the maximum rated power of single cell of electrolyser, as given in the denominator of equation (13). As mentioned before, the electrolyser cells are connected in series, therefore, same amount of current is flowing through each cell, given by equation (14).

$$
I_{E}=\frac{\eta_{C D C} \times P_{\text {excess }}}{N_{E C} \times U_{E}}
$$


The voltage characteristics of considered electrolyser, as presented in [33], can be found by equation (15).

$$
U_{E}=U_{\text {rev }}+\frac{r_{1}+r_{2} T_{E}}{A_{E}} I_{E}+\left(S_{1}+S_{2} T_{E}+S_{3} T_{E}^{2}\right) \cdot \log \left(\frac{t_{1}+\frac{t_{2}}{T_{E}}+\frac{t_{3}}{T_{E}^{2}}}{A_{E}} I_{E}+1\right)
$$

The voltage of electrolyser is essential only to start the electrolysis process. On the other hand, the total production of hydrogen is actually depending upon the amount of current flowing through the electrolyser as it is the amount of electrons that flow and split the water molecules. Therefore, the total output of electrolyser in form of hydrogen and oxygen gases production is depending upon its current consumption, as given by equation (16). The hydrogen production is twice the oxygen production.

$$
\dot{n}_{E, H 2}=\eta_{E F} \frac{N_{E C} I_{E}}{n F}=2 \dot{n}_{E, O 2}
$$

The Faraday efficiency is assumed to be $95 \%$ for a uniform operating temperature of $80^{\circ} \mathrm{C}$.

\subsection{Proton Exchange Membrane (PEM) Fuel Cell}

This sub-section is related to the lower right part of Fig. 2 when power produced by the CPV system is not enough to meet the load requirement. In order to supply back electricity to the system, a fuel cell based system is considered which utilizes stored hydrogen and oxygen according to the amount of electricity needed by the system. The fuel cell unit considered for this study is a proton exchange membrane (PEM) type unit for which the single cell characteristics are discussed in [33]. The voltage output of fuel cell is given by equation (17).

$$
U_{F}=U_{o}-b \cdot \log \left(\frac{I_{F}}{A_{F}}\right)-R\left(\frac{I_{F}}{A_{F}}\right)
$$

Like electrolyser, the main design parameter for fuel cell is also its power rating or the amount of cells joined in series. Therefore, maximum number of cell for fuel cell unit is depending upon the maximum amount of power supplied by the fuel cell i.e. maximum load requirement of the consumer, as given by equation (18).

$$
N_{F C}=\frac{L_{\max }}{\eta_{C D C} \times \eta_{D C / A C} \times P_{F C, \max }}
$$

By knowing the number of cells, the amount of current flowing through the system can be determined by equation (19) if power deficiency is known.

$$
I_{F}=\frac{P_{r e q}}{\eta_{C D C} \times \eta_{D C / A C} \times N_{F C} \times U_{F}}
$$

Similar to electrolyser, the total output and the rate of gas consumption of fuel cell are depending upon its current production, as given by equation (20).

$$
\dot{n}_{F, H 2}=\eta_{F F} \frac{N_{F C} I_{F}}{n F}=2 \dot{n}_{F, O 2}
$$




\subsection{Hydrogen Compressor}

This sub-section is related to the middle right part of Fig. 2, under system load. For standalone operation and steady power supply of the proposed solar system, the excess produced energy is converted into hydrogen and oxygen by electrolysis of water. Such produced gases also require a reliable and compact storage system which can readily supply back these gases when needed, without any external assistance. Mechanical gas compression system with cylinder storage provide reliable and long term gas storage solution with compact size. Therefore, in order to model such compression unit, a thermodynamic performance of mechanical compressor is considered as given by equation (21) [34]. It is polytropic process equation which is applied with first law of thermodynamics in terms of power required to the change the temperature of gas i.e. before and after compression.

$$
P_{c o m}=\left(\dot{n}_{E, H 2} \times \frac{M_{H 2}}{1000}\right) \times C P_{H} \times \frac{T_{c o m}}{\eta_{D C / A C} \times \eta_{c o m}}\left\{\left(\frac{P_{t a}}{P_{E}}\right)^{\left(\frac{r-1}{r}\right)}-1\right\}
$$

\subsection{Hydrogen Storage Cylinder}

This sub-section is related to the lower mid part of Fig. 2. As the compressed gases are stored into cylinders, therefore, it is also very important to model the state of the storage cylinder in form of its pressure, in order to estimate the available energy stored. In order to model the performance of the storage cylinder, an ideal gas equation (22) considered with compressibility factor ' $Z$ ' which the stage of the cylinder in form of its pressure as volume is constant. In this study, the value of compressibility factor is obtained from the data table of real hydrogen gas for $3.34 \mathrm{~m}^{3}$ tank at $33^{\circ} \mathrm{C}$.

$$
P_{t a}=\frac{n_{t a} R T_{t a}}{V_{t a}} \times Z_{H}
$$

\subsection{Hot water storage tank}

This sub-section is also related to the lower mid part of Fig. 2. The waste heat recovered from the back plate of multi-junction solar cells in CPV system, through hot water circulation, is stored into hot water storage tanks as shown in Fig. 1. A one dimensional transient model is developed for stratified hot water tank. The tank is assumed to be divided into finite number of layers with thermal uniformity. An energy balance is applied to control volume of each thermal layer and based upon the mass balance for convective and conductive flows, a set of temperature differential equations are written below to predict the thermal state of hot water storage tanks during operation.

$$
\begin{aligned}
& \left.F_{c, i}\left[m_{c} C_{p, w}\left(T_{c, o}-T_{T, 1}\right)\right]+F_{D, j}\left[m_{T} C_{p, w}\left(T_{T, 2}-T_{T, 1}\right)\right]\right]=V_{L} \rho_{w} C_{p, w} \frac{T_{T, 2}^{t}-T_{T, 1}^{t-1}}{\Delta t} \\
& +k A \frac{T_{T, 2}-T_{T, 1}}{\Delta h} \\
& F_{c, i}\left[m_{c} C_{p, w}\left(T_{T, n-1}-T_{T, n}\right)\right]+F_{D, j}\left[m_{T} C_{p, w}\left(T_{T, n+1}-T_{T, n}\right)\right] \\
& +k A\left[\frac{T_{T, n-1}-T_{T, n}}{\Delta h}-\frac{T_{T, n}-T_{T, n+1}}{\Delta h}\right]=V_{L} \rho_{w} C_{p, w} \frac{T_{T, n}^{t}-T_{T, n}^{t-1}}{\Delta t}
\end{aligned}
$$




$$
\begin{aligned}
& F_{c, i}\left[m_{c} C_{p, w}\left(T_{T, n}-T_{T, n+1}\right)\right]+F_{D, j}\left[m_{T} C_{p, w}\left(T_{T, n+2}-T_{T, n+1}\right)\right] \\
& \left.+F_{D M, j}\left[m_{m} C_{p, w}\left(T_{R}-T_{T, n+1}\right)\right]+k A\left[\frac{T_{T, n}-T_{T, n+1}}{\Delta h}-\frac{T_{T, n+1}-T_{T, n+2}}{\Delta h}\right]\right\rangle=V_{L} \rho_{w} C_{p, w} \frac{T_{T, n+1}^{t}-T_{T, n+1}^{t-1}}{\Delta t} \\
& \left.F_{c, i}\left[m_{c} C_{p, w}\left(T_{T, n+1}-T_{T, n+2}\right)\right]+F_{D, j}\left[m_{T} C_{p, w}\left(T_{R}-T_{T, n+2}\right)\right]\right\rangle=V_{L} \rho_{w} C_{p, w} \frac{T_{T, n+2}^{t}-T_{T, n+2}^{t-1}}{\Delta t} \\
& +F_{D M, j}\left[m_{m} C_{p, w}\left(T_{R}-T_{T, n+2}\right)\right]+k A\left[\frac{T_{T, n+1}-T_{T, n+2}}{\Delta h}\right]
\end{aligned}
$$

Where ' $F_{C}$ ', ' $F_{D}$ ' and ' $F_{D M}$ ' represents the control function for collector discharge, hot water discharge and mixing water discharge, respectively for which the value can be either 0 or 1 depending upon the state of operation of tank. However, subscripts ' $i$ ' and ' $\mathrm{j}$ ' represents the tank number associated with the collector discharge, respectively.

\subsection{Adsorption chiller}

This sub-section is related to the middle part of Fig. 2, to calculate the thermal energy consumption for cooling. The adsorption chiller is considered as the auxiliary cooling system which work on the heat energy recovered during operation of CPV system. The performance model of the adsorption system is based upon its thermal energy consumption which can be found by knowing the COP of the considered chiller.

$$
C O P_{A D}=\frac{C E_{A D}}{Q_{A D}}
$$

The cooling effect of adsorption chiller ' $\mathrm{CE}_{\mathrm{AD}}$ ' is an optimization parameter which has to be find out as per available recovered energy.

$$
Q_{A D}=\frac{L_{c o o l} \times F R_{A D}}{C O P_{A D}}
$$

This heat energy is supplied to the adsorption chiller in form hot water, as given by equation (26).

$$
Q_{A D}=\dot{m}_{A D} \times C_{p, w} \times\left(T_{A D}-T_{A D, \mathrm{R}}\right)
$$

By knowing the thermal energy requirement of the adsorption chiller, the return hot water temperature can be found by equation (27).

$$
T_{A D, \mathrm{R}}=T_{A D}-\left[\frac{L_{c o o l} \times F R_{A D}}{C O P_{A D} \times m_{A D} \times C_{p, w}}\right]
$$

\subsection{Mechanical Vapor Compression (MVC) Chiller}

This sub-section is also related to the middle part of Fig. 2, but to calculate the electrical energy consumption for cooling. The performance of mechanical vapor compression (MVC) chiller is also depending upon the COP of the considered system. However, the most important factor in the operation of MVC is its operating capacity that is depending upon the hot water storage system. If the supply temperature of hot water storage tank is enough to operate adsorption chiller then MVC operates in part load conditions according to the share of cooling load taken by adsorption chiller. If the hot water storage unit does not have enough energy to operate adsorption chiller, 
then MVC operates its full capacity to cover $100 \%$ cooling load requirements, as given by equations (28) and (29).

$$
\begin{aligned}
& \text { if }\left(T_{T, 1}>T_{A D}\right) \\
& L_{\text {Elect }}=\left[\frac{L_{\text {cool }} \times\left(1-F R_{A D}\right)}{C O P_{C H}}\right] \\
& \text { if }\left(T_{T, 1}<T_{A D}\right) \\
& L_{\text {Elect }}=\left[\frac{L_{\text {cool }}}{C O P_{C H}}\right]
\end{aligned}
$$

\section{Optimization Objective Functions and Strategy}

The main objective of current chapter to develop a sustainable cooling system based upon solar energy which can operate in standalone mode, without any external assistance and supply. Energy storage systems are coupled with primary supply unit, to handle intermittency. Moreover, the performance models for every components, at any operating condition, is developed in the previous section. However, the main question is, what should be the optimum size of each component to meet the mentioned targets. To be precise, the above mentioned targets have been defined in mathematical form as three objective functions, equations (30), (31) and (32), for the optimization of proposed system configuration.

$$
\begin{gathered}
P S F T=\sum_{\text {year }} t_{P F}=0 \\
L 1<S T_{H 2(f)}-S T_{H 2(i)}<L 2 \\
C_{A T}=C_{C P V}+C_{E L}+C_{F C}+C_{S T H 2}+C_{S T O 2}+C_{c o m}+C_{A D}+C_{M V C}+C_{H W T}+C_{H X} \\
C_{C P V}=\left(N P_{C P V} \times N_{C M} \times P_{M J C, \max }\right) \times\left[C C_{C P V}+\left(O M C_{C P V} \times C R F\right)\right] \quad(32 \mathrm{~A}) \\
C_{E / F C}=\left(N_{E C / \mathrm{FC}} \times P_{E / F C \text {,max }}\right) \times\left[C C_{E / F C}+\left(R C_{E / F C} \times S P P W\right)+\left(O M C_{E / F C} \times C R F\right)\right] \\
C_{S T H 2 / O 2 / H W T}=S T M_{H 2 / O 2 / H W T} \times\left[C C_{S T H / / O 2 / H W T}+\left(O M C_{S T H 2 / O 2 / H W T} \times C R F\right)\right] \\
C_{c o m / A D / M V C / \mathrm{HX}}=P_{\text {com/AD/MVC/HX }} \times\left[C C_{c o m / A D / M V C / \mathrm{HX}}+\left(O M C_{c o m / A D / M V C / \mathrm{HX}} \times C R F\right)\right] \\
C R F=\left[\frac{i \times(1+i)^{L}}{(1+i)^{L}-1}\right] \quad(32 \mathrm{E}) \\
S P P W=\frac{1}{(1+i)^{y}} \quad(32 \mathrm{~F})
\end{gathered}
$$

The first and most important objective function, equation (30), is the uninterrupted power supply, which is defined in form of power supply failure time and for uninterrupted power, its value must be zero. Therefore, any configuration for which PSFT factor is greater than zero, is not acceptable. In addition, the system is utilizing energy storage system to avoid intermittency. Therefore, the state of stored energy must be maintained within certain limit, given by equation (31), for steady and optimum operation. It must be noted that only hydrogen storage is considered as water and oxygen storage are directly linked to it. Water and oxygen storage are of same size as com- 
pared to each other but half the size of hydrogen storage, in terms of moles. On the other hand, the hot water storage is taken as variable parameter which has to be optimized according to available thermal energy. Last and most important objective function is the overall cost of the system, given by equation (32). As the steady power supply can be easily obtained by oversizing system, therefore, the objective of this study is to find out optimum and economical system configuration by meeting the other two objective function. The overall cost function includes installation/capital cost (CC), operation \& maintenance cost (OMC) and replacement cost (RC). The detailed costing functions for each of the system components are given by equations (32A)-(32D). The factors ' $C R F$ ' and 'SPPW' in equation (32E)-(32F) represent capital recovery factor and single payment present worth, respectively. 


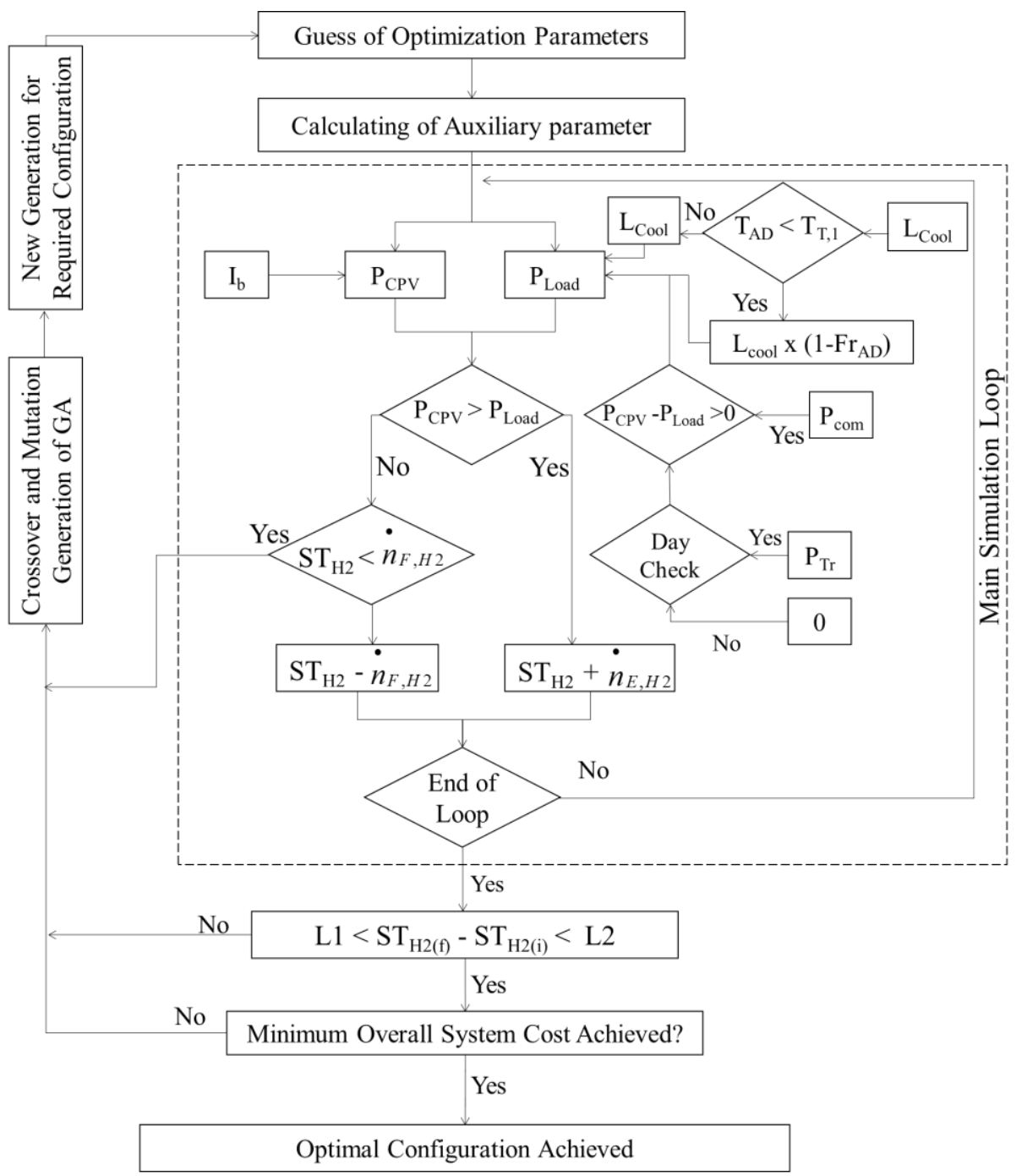

Fig.5. Optimization Strategy for Proposed System Configuration using micro-GA.

To achieve the optimum configuration of proposed system, as per defined objective functions, an optimization strategy is developed in Fig. 5, according to energy management strategy shown in Fig. 2. However, the shown optimization strategy is implemented by using micro genetic algorithm (micro-GA) using FORTRAN programming language. The optimization programs is developed in two parts. The first part deal with the performance simulation of the proposed system configuration, at any operation condition, according to their energy management strategy. The second part deals with the optimization of system sizing parameters according to defined objective function. The optimized parameters considered for current study are normal of CPV modules, number of hot water storage tanks, percentage share of adsorption 
chiller and initial amount of hydrogen storage. However, other parameters are calculated from the optimization parameters. The micro-GA algorithm is implemented with population size of 5 with maximum 300 generation. The optimization curve and the system performance characteristics are discussed in the next section.

\section{$5 \quad$ Optimization Results and Performance Analysis}

According to defined optimization strategy and objective function, the micro genetic algorithm (micro-GA) is implemented for the standalone operation of proposed system configuration as per defined energy management strategy and the optimization results are shown in Fig. 6. From the results, first of all, it is clear that the 300 generation were enough to obtain the optimum results. However, convergence of the programme i.e. minimum cost, was obtained after 120 generations. On the other hand, it can also be seen that for all of the configurations, the PSFT factor is zero, which ensure the steady and uninterrupted power supply to the load. From energy storage point of view, the difference in the state of hydrogen cylinder, before and after the operation, is within the assumed limits of ' $\mathrm{L} 1=-10 \mathrm{~kg}$ ' and ' $\mathrm{L} 2=35 \mathrm{~kg}$ '. Such developed strategy and configuration can be applied to the cooling system of any capacity, to achieve their optimum operating configuration, by utilizing the maximum potential of solar energy in form of CPV system.

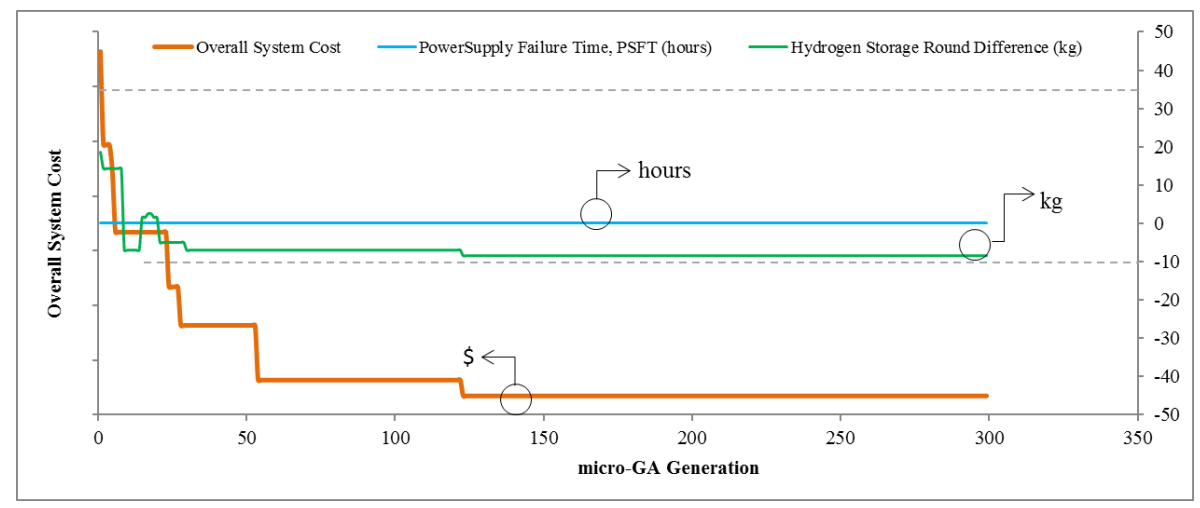

Fig.6. System Optimization Curve for micro-GA.

As mentioned before, CPV system provides the best of the solar energy system with highest high quality energy conversion efficiency. Based upon the proposed configuration, the performance of the proposed CPV system, as per actual received DNI data, is shown in Fig. 7. It can be seen that the CPV system showed maximum electrical efficiency of 27-28\%. However, the CPV-Hydrogen system showed maximum efficiency of $18 \%$ which is about two fold higher than the efficiency of conventional PV systems. The performance curves highlights the variation in system output during whole day operation. It can be seen that both electrical and hydrogen efficiency of the CPV system are first increasing and then decreasing toward middle of the day. In case 
of hydrogen production, the decrease in overall efficiency is due to decline in the electrolyser efficiency. As the intensity of solar radiations increases from morning to noon, the power output of CPV system also increases, which is supplied to electrolyser. With increase in supplied power, its operating voltage also increase, due to which its efficiency declines in inverse manners, as shown in Fig. 7. On the other hand, in case of CPV electrical efficiency, the decline in efficiency is due to increase cell temperature [32], as discussed before. As the received DNI increases, the concentration at cell area also increases and so as the waste heat. Therefore, electrical efficiency of CPV slightly decreases. But overall electrical and thermal efficiency of CPV-Thermal (CPVT) remain steady as where electrical efficiency decrease due to increased heat, at the same time, thermal efficiency increases with better heat recover. The maximum value of $71 \%$ is presented as solar energy efficiency in case of CPVT system.

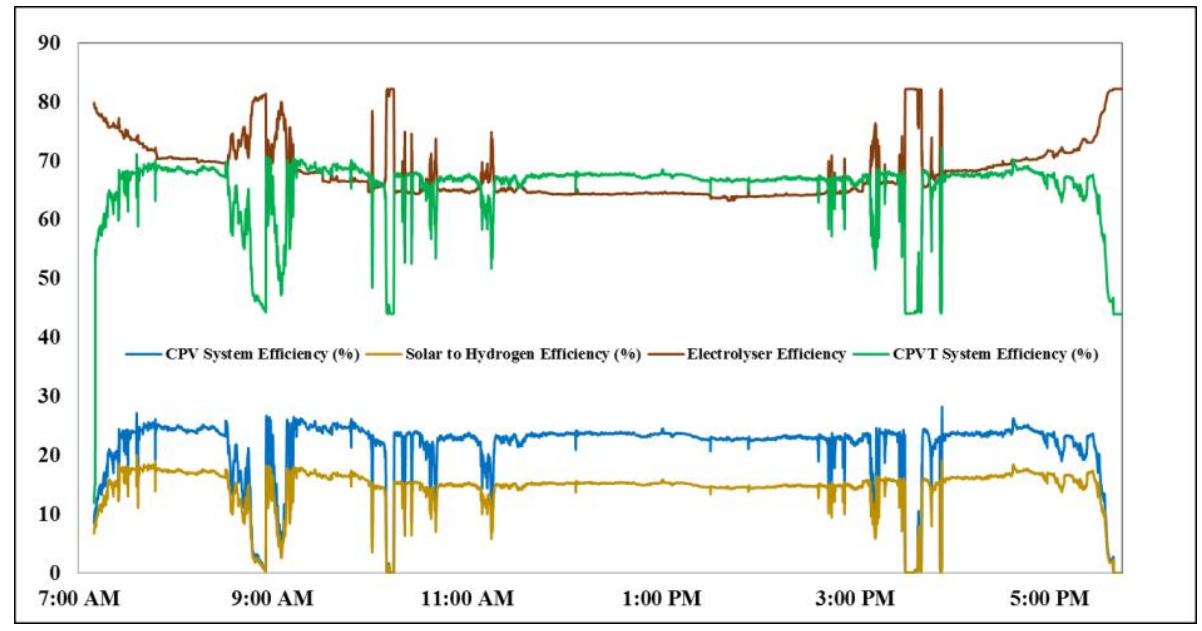

Fig.7. Performance Characteristics of Proposed Concentrated Photovoltaic (CPV) System.

The most interesting aspect here is the overall highest efficiency of CPVT system. Although, all of the converted solar energy is not available in high grade form but it can be fully utilized as per application, like proposed CPVT-cooling system. The recovered heat is enough to operate adsorption chiller which provide auxiliary support to main mechanical chiller. Thus, the proposed configuration CPVT system provides a sustainable solution to our cooling needs, using combined chiller system, operated by solar energy. However, the hydrogen energy storage provides a reliable and long term energy storage solution to handle the solar intermittency issues as it can be scaled up to any size of the system and can be stored for long period, as compared to battery, assuming no leak. 


\section{Summary of Chapter}

In order to fulfill increasing global cooling needs and due to damaging effects of fossil fuel use, a sustainable solution is proposed using highly efficient solar photovoltaic system i.e. concentrated photovoltaic (CPV). Due to its operation at high solar concentration, a heat recovery system is also coupled which increase the overall solar energy conversion efficiency of CPVT system as high as $71 \%$. As both electrical and thermal energies are received as output, therefore, a combine cooling system is proposed, which is based upon electricity operated mechanical vapor compression (MVC) chiller and thermal operated adsorption. By keeping in the issue of solar intermittency and need of steady power supply, hydrogen production is utilized as long term electrical energy storage system, and hot water is considered for thermal energy storage.

The main challenge in such proposed configuration is its optimized design in which all of the system components are of perfect size, according to their need, with minimum cost. Therefore, a detailed performance model and optimization strategy is proposed for standalone operation of CPVT based combined cooling system. The optimization algorithm and strategy is proposed using micro genetic algorithm (micro-GA) which finds out the optimum size of every component of the system, for uninterrupted power supply with minimum system cost. As none of the commercial simulation software is capable of handling CPV, therefore, the proposed strategy can also be integrated with them to enhance their capability. Moreover, such model can be used to optimize CPV system for any application and capacity for steady power supply.

\section{References}

1. IPCC, Renewable Energy Sources and Climate Change Mitigation. Special Report of the Intergovernmental Panel on Climate Change. 2012.

2. Shahzad MW, Burhan M, Ang L, Ng KC. Adsorption desalination-Principles, process design, and its hybrids for future sustainable desalination. In Emerging Technologies for Sustainable Desalination Handbook 2018 (pp. 3-34).

3. Ng KC, Burhan M, Shahzad MW, Ismail AB. A Universal Isotherm Model to Capture Adsorption Uptake and Energy Distribution of Porous Heterogeneous Surface. Scientific Reports $2017,7(1), 10634$.

4. Burhan M. (2015). Theoretical and Experimental Study of Concentrated Photovoltaic (CPV) System with Hydrogen Production as Energy Storage (Doctoral dissertation).

5. Burhan M, Shahzad MW, Ng KC. Sustainable Cooling with Hybrid Concentrated Photovoltaic Thermal (CPVT) System and Hydrogen Energy Storage. International Journal of Computational Physics Series 2018, 1(2), 40-51.

6. Burhan M, Shahzad MW, Ng KC. Energy distribution function based universal adsorption isotherm model for all types of isotherm. International Journal of Low-Carbon Technologies 2018, https://doi.org/10.1093/ijlct/cty031.

7. Burhan M., Chua KJE, Ng KC. Simulation and development of a multi-leg homogeniser concentrating assembly for concentrated photovoltaic (CPV) system with electrical rating analysis. Energy Conversion and Management 2016, 116, 58-71. 
8. Burhan M, Chua KJE, Ng KC. Sunlight to hydrogen conversion: Design optimization and energy management of concentrated photovoltaic (CPV-Hydrogen) system using micro genetic algorithm. Energy 2016, 99, 115-128.

9. Oh SJ, Ng KC, Thu K, Chun W, Chua KJ. Forecasting long-term electricity demand for cooling of Singapore's buildings incorporating an innovative air-conditioning technology. Energy and Buildings 2016, 127, 183-93.

10. Gordon JM, Ng KC. Cool thermodynamics. Viva Books, 2008.

11. Shahzad MW, Burhan M, Ang L, Ng KC. Energy-water-environment nexus underpinning future desalination sustainability. Desalination 2017, 413, 52-64.

12. Shahzad MW, Burhan M, Ng KC. Energy Storage \& Desalination. International Journal of Computational Physics Series 2018, 1(2), 52-60.

13. Shahzad MW, Burhan M, Ghaffour N, Ng KC. A multi evaporator desalination system operated with thermocline energy for future sustainability. Desalination 2018, 435, 268-77.

14. Burhan M, Shahzad MW, Ng KC. Development of performance model and optimization strategy for standalone operation of CPV-hydrogen system utilizing multi-junction solar cell. International Journal of Hydrogen Energy 2017, 42(43), 26789-803.

15. Saadi A, Becherif M, Ramadan HS. Hydrogen production horizon using solar energy in Biskra, Algeria. International Journal of Hydrogen Energy 2016, 41(47), 21899-912.

16. Burhan M, Oh SJ, Chua KJ, Ng KC. Solar to hydrogen: Compact and cost effective CPV field for rooftop operation and hydrogen production. Applied energy 2017, 194, 255-66.

17. Burhan M, Chua KJE, Ng KC. Electrical rating of concentrated photovoltaic (CPV) systems: long-term performance analysis and comparison to conventional PV systems. International Journal of Technology 2016, 7(2), 189-196. DOI: 10.14716/ijtech.v7i2.2983.

18. Muhammad B, Seung JO, Ng KC, Chun W. Experimental Investigation of Multijunction Solar Cell Using Two Axis Solar Tracker. In Applied Mechanics and Materials 2016, 819, 536-540. DOI: 10.4028/www.scientific.net/AMM.819.536.

19. Burhan M, Shahzad MW, Oh SJ, Ng KC. A pathway for sustainable conversion of sunlight to hydrogen using proposed compact CPV system. Energy Conversion and Management 2018, 165, 102-12.

20. Green MA, Emery K, Hishikawa Y, Warta W, Dunlop ED. Solar cell efficiency tables (Version 45). Progress in photovoltaics: research and applications 2015, 23(1), 1-9.

21. Burhan M, Shahzad MW, Choon NK. Hydrogen at the Rooftop: Compact CPV-Hydrogen system to Convert Sunlight to Hydrogen. Applied Thermal Engineering 2018, 132, 154 164.

22. Burhan M, Chua KJE, Ng KC. Long term hydrogen production potential of concentrated photovoltaic (CPV) system in tropical weather of Singapore. International Journal of Hydrogen Energy 2016, 41(38), 16729-16742.

23. Oh SJ, Burhan M, Ng KC, Kim Y, Chun W. Development and performance analysis of a two-axis solar tracker for concentrated photovoltaics. International Journal of Energy Research 2015, 39(7), 965-76.

24. Burhan M, Shahzad MW, Ng KC. Long-term performance potential of concentrated photovoltaic (CPV) systems. Energy Conversion and Management 2017, 148, 90-9.

25. HOMER (Hybrid Optimization of Multiple Energy Resources). Available from: http://www.homerenergy.com/software.html.

26. Bernal-Agustin JL, Dufo-Lopez R. Simulation and optimization of stand-alone hybrid renewable energy systems. Renewable and Sustainable Energy Reviews 2009; 13; 2111 2118. 
27. iHOGA (Improved Hybrid Optimization by Genetic Algorithms). Available from: http://personal.unizar.es/rdufo/index.php?option=com_content\&view=article\&id=2\&Itemi $\mathrm{d}=104$ \&lang=en.

28. Nishioka K, Takamoto T, Agui T, Kaneiwa M, Uraoka Y, Fuyuki T. Annual output extimation of concentrator photovoltaic systems using high-efficiency InGaP/InGaAs/Ge triple-junction solar cells based on experimental solar cell's characteristics and field-test meteorological data, Solar Energy Materials \& Solar Cells 2006; 90; 57-67.

29. Yu X, Gen M. Introduction to evolutionary algorithms. Springer Science \& Business Media. 2010.

30. Burhan M, Oh SJ, Chua KJE, Ng KC. Double lens collimator solar feedback sensor and master slave configuration: Development of compact and low cost two axis solar tracking system for CPV applications. Solar Energy 2016, 137, 352-363.

31. ArzonSolar. http://www.arzonsolar.com/wp-content/uploads/2015/02/uModuleDatasheet.pdf. Date retrieved: 25-02-2017.

32. Bennett JM, Ashley EJ. Infrared reflectance and emittance of silver and gold evaporated in ultrahigh vacuum. Applied Optics 1965, 4(2), 221-4.

33. Ulleberg $\varnothing$. Stand-Alone Power Systems for the Future: Optimal Design, Operation \& Control of Solar-Hydrogen Energy Systems. Ph.D. Thesis, Department of Thermal Energy and Hydropower, Norwegian University of Science and Technology, Trondheim, Norway 1998.

34. Li CH, Zhu XJ, Cao GY, Sui S, Hu MR. Dynamic modeling and sizing optimization of stand-alone photovoltaic power systems using hybrid energy storage technology. Renewable Energy 2009; 34(3), 815-826. 